\title{
Plasmodium vivax infection in Anajás, State of Pará: no differential resistance profile among Duffy-negative and Duffy-positive individuals
}

Tarcisio AA Carvalho ${ }^{1}$, Maíse G Queiroz ${ }^{1}$, Greice L Cardoso ${ }^{1}$, Isabela G Diniz ${ }^{1}$, Aylla NLM Silva ${ }^{1}$, Ana YN Pinto ${ }^{2}$ and João F Guerreiro ${ }^{1 *}$

\begin{abstract}
Background: There is large body of evidence that states that invasion of Plasmodium vivax requires the Duffy antigen, but the universality of this specificity is certainly now under question with recent reports showing that in some parts of the world P. vivax infects and causes disease in Duffy-negative people. These findings reinforce the idea that this parasite is rapidly evolving, being able to use other receptors than Duffy to invade the erythrocytes, which may have an enormous impact in $P$. vivax current distribution. The presence of $P$. vivax infection in Duffy-negative individuals was investigated in a cross-sectional study conducted in Anajás, Archipelago of Marajó, State of Pará, which is an area of malaria transmission in the Brazilian Amazonia.

Methods: Duffy genotyping and Plasmodium species diagnostic assays were performed successfully in 678 individuals. An allele-specific primer polymerase chain reaction (PCR) technique was used for Duffy blood group genotyping. Identification of Plasmodium species was achieved by conventional blood smear light microscopy and a TaqMan-based real-time PCR method to detect mitochondrial genome of Plasmodium falciparum and $P$. vivax.

Results: Plasmodium spp. infection was detected in 137 samples (20.2\%). Prevalence of each Plasmodium species was $13.9 \%$ P. vivax, $5.8 \%$ P. falciparum, and $0.6 \%$ P. vivax plus P. falciparum. Overall, $4.3 \%$ (29/678) were genotyped as Duffy-negative $\left(F Y^{*} B^{E S} /{ }^{*} B^{E S}\right)$. Among Duffy-negative individuals $6.9 \%$ were $P$. vivax $P C R$ positive and among Duffy-positive $14.2 \%$ were $P$. vivax PCR positive. Although lower, the risk of Duffy-negatives to experience a $P$. vivax blood stage infection was not significantly different to that of Duffy-positives. Furthermore, the genotypic and allelic frequencies of the Duffy blood group among $P$. vivax-infected patients and in the control group did not differ significantly, also suggesting no reduction in infection rates among the carriers of $F Y^{*} B^{E S}$ allele.

Conclusions: The data obtained in Anajás showed no differential resistance vivax malaria among Duffy-negative and Duffy-positive individuals. This result needs additional confirmation through a deeper evaluation in a larger sample of patients with P. vivax malaria and molecular parasite characterization. Nonetheless, this genetic profile of the parasite may be contributing to the high incidence of malaria in the municipality.
\end{abstract}

Keywords: Vivax malaria, Duffy blood group, Brazilian Amazonia

\footnotetext{
* Correspondence: joao.guerreiro@ig.com.br

'Laboratório de Genética Humana e Médica, Instituto de Ciências Biológicas, Universidade Federal do Pará, Cidade Universitária Prof. José da Silva Neto, Rua Augusto Corrêa, N 01 , Guamá, CEP 66075-110, Belém, PABrasil Full list of author information is available at the end of the article
} 


\section{Background}

Five species, Plasmodium malariae, Plasmodium ovale, Plasmodium falciparum, Plasmodium vivax and, recently, Plasmodium knowlesi, are recognized as natural malaria parasites of humans. Due to its biology, P. vivax is the most widely transmitted, occurring in temperate latitudes, arid regions, at high altitude and in other environments that are inhospitable to $P$. falciparum. Outside tropical Africa, in Asia and the Western Pacific, and in Central and South America, the most prevalent of these parasites is $P$. vivax. By contrast, in sub-Saharan Africa, where malaria transmission is otherwise more intense than anywhere else in the world, cases of $P$. vivax are greatly outnumbered by those due to $P$. falciparum, and $P$. vivax is almost undetectable in the local human populations. In Brazil, the incidence of malaria is almost exclusively (99.8\%) of the cases restricted to the region of the Amazon Basin, and is caused by three species of Plasmodium: P. vivax (that accounts for $83.7 \%$ of the registered cases), P. falciparum (causing $16.3 \%$ of the cases) and P. malariae (rarely observed). No autochthonous transmission of P. ovale and P. knowlesi occurs [1,2].

The gap in distribution of $P$. vivax in Africa compared to the rest of the world is viewed as the consequence of the lack of expression of the Duffy antigen on the red cells (Duffy-negative phenotype), which mediates invasion of reticulocytes by $P$. vivax, and is highly predominant in the African populations in contrary to the observed in European, Asian and American populations in whom the Duffy-positive phenotype is more common. The pattern of Duffy-blood group distribution is attributed to a positive natural selection, since $P$. vivax requires the presence of Duffy antigen receptor for chemokines on the red blood cells' (RBC) surface to be able to invade cells and cause disease (reviewed in [3-6]).

The Duffy blood group locus, at position q21-q25 on chromosome 1 [7], is characterized by three main alleles: $F Y^{*} A, F Y^{*} B$ and $F Y^{* *} B^{E S}$. The $F Y^{* *} A$ and $F Y^{*} B$ alleles are distinguished by a missense mutation, which results in a single amino acid difference and gives the common Fy $(\mathrm{a}+\mathrm{b}-), \mathrm{Fy}(\mathrm{a}-\mathrm{b}+)$ and $\mathrm{Fy}(\mathrm{a}+\mathrm{b}+)$ phenotypes [8-11]. The $F Y^{*} B^{E S}$ allele, which corresponds to the Fy(a-b-) serological phenotype (i e, the absence of Fy antigen), is due to a T-33C point mutation on the $F Y^{*} B$ gene promoter, which abolishes the erythroid gene expression by disrupting a binding site for the GATA-1 erythroid transcription factor and results in the elimination of the transcription of FY mRNA in RBCs, but not in other cell types $[12,13]$. The same mutation associated with the $F Y^{*} A$ variant $\left(F Y^{* *} A^{E S}\right.$ allele) was already identified at low frequencies in individuals living in a $P$. vivax-endemic region of Papua New Guinea [14,15].

Although there is a large body of evidence that states that invasion of $P$. vivax requires the Duffy antigen, the universality of the specificity is certainly now under question with recent reports that in some parts of the world $P$. vivax infects and causes disease in Duffy-negative people: in western Kenya [16], in the Western Brazilian Amazon region [17,18], in Madagascar [19], in African West Coast (Equatorial Guinea and Angola) [20], and in Mauritania, north-west Africa [21]. These findings reinforce the idea that this parasite is rapidly evolving, being able to use other receptors than Duffy to invade the erythrocytes, which may have an enormous impact in P. vivax current distribution [20].

The aims of this study were to investigate the presence of $P$. vivax infection in Duffy-negative individuals from Anajás, State of Pará, an area of malaria transmission in the Brazilian Amazonia, using an allele-specific primer polymerase chain reaction (PCR) technique for Duffy blood group genotyping, and conventional blood smear light microscopy and a TaqMan-based real-time PCR method to detect $P$. falciparum and $P$. vivax.

\section{Methods}

\section{Ethics statement}

The study was approved by the Ethics Committee of João de Barros Barreto Hospital, Federal University of Pará, Belém, State of Pará, Brazil, and health authorities from the municipal district of Anajás.

\section{Sampling}

The samples for this study were collected in August 2009 in a cross-sectional study conducted in Anajás, Archipelago of Marajó, State of Pará, Eastern Brazilian Amazon (00 59'13"S; 49 56'24"W). Anajás was the municipal district that presented the highest index of malaria in the State of Pará in the year of 2009, with 26,043 positive cases in a population of 27,385 inhabitants, resulting in an Annual Parasitic Index (IPA) of 951/1,000 inhabitants [22].

In total, 738 patients were examined, 339 of them living in the city and 399 in two riverine communities in rural Anajás (Vencedora, $\mathrm{n}=212$ and Luciana, $\mathrm{n}=187$ ). Luciana village is located on the left bank of the River Mocoões (050'27.81"S;4950'9.14"W), about $25 \mathrm{~km}$ downstream of the city of Anajás. Vencedora village is located on the right bank of the Alto Rio Anajás $\left(0^{\circ} 58^{\prime} 52.26^{\prime \prime S} ; 49^{\circ} 58^{\prime} 08.33^{\prime \prime W}\right)$, about $5 \mathrm{~km}$ upstream from the city of Anajás. The patients were clinically examined, and $2 \mathrm{~mL}$ of blood were drawn for thick blood smears preparation and for molecular diagnosis of malaria infection. Microscopic parasitaemia examinations were performed by three experienced malaria field microscopists from the Federal University of Pará (UFPA) on slides using the thick film method and the results were reported as parasites/ $\mu \mathrm{L}$ [23]. 


\section{DNA extraction}

DNA was extracted from $300 \mu \mathrm{L}$ of EDTA-treated blood using the NeoIsoColumn kit (One Lambda Inc., San Diego, CA, USA) according to the manufacturer's instructions. DNA was eluted in $200 \mu \mathrm{L}$ of elution buffer (provided with the kit).

\section{Real-time PCR}

For real-time PCR, Primer Express software (Life Technologies, Foster City, CA, USA) was used to design specific primers (forward and reverse) targeting a mitochondrial DNA (mtDNA) sequence common to all Plasmodium spp, and TaqMan ${ }^{\mathrm{TM}}$ fluorescence-labelled probes to hybridize differentially in $P$. vivax or P. falciparum, enabling species identification. The following oligonucleotides primers and probes were used: forward 5'-ACCTCCAGGCAAAGAAAATGAC-3', reverse 5'GGCGAGAAGGGAAGTGTGTTT-3' and probes 5'AACGGAATCAGTTAA-3'-FAM for $P$. vivax and 5'-ACGGAATCAATTAAC-3'-VIC for $P$. falciparum. DNA templates were amplified in an Applied Biosystems 7500 analytical PCR system (SDS version 1.7). Briefly, a $50 \mu \mathrm{L}$ PCR mixture was performed using 20-100 ng/ $\mu \mathrm{L}$ of purified DNA template, $25 \mathrm{~mL}$ of TaqMan $^{\text {TM }} 2$ X (Life Technologies) universal PCR master mix, and a final concentration of $300 \mathrm{nM}$ of each parasite species-specific primer and $200 \mathrm{nM}$ of each corresponding probe. Amplification and detection were performed under the following conditions: $2 \mathrm{~min}$ at $50^{\circ} \mathrm{C}$ to achieve optimal AmpErase uracil- $\mathrm{N}$-glycosylase activity, $10 \mathrm{~min}$ at $95^{\circ} \mathrm{C}$ to activate the AmpliTaq Gold DNA polymerase, and 45 cycles of $15 \mathrm{sec}$ at $95^{\circ} \mathrm{C}$ and $1 \mathrm{~min}$ at $60^{\circ} \mathrm{C}$ using a 7500 Real-Time PCR System (Life Technologies, Foster City, CA, USA). Each experiment included one reaction mixture without DNA as a negative control.

\section{DNA sequence analysis}

The specificity of the assay was confirmed by sequencing the PCR products from all positive samples using a Big Dye terminator sequencing kit (Applied Biosystems) on an ABI 3130 sequencer (Applied Biosystems) following the manufacturer's instructions. In samples with positive results to $P$. falciparum, this procedure is particularly necessary to exclude possible infections by $P$. malariae, $P$. knowlesi and P. ovale, since the employed probe can identify all these species. The sequences obtained were aligned with those deposited in GenBank using the BLAST (Basic Local Alignment Search Tool) program.

\section{Duffy blood group genotyping}

The samples were genotyped using an allele-specific primer polymerase chain reaction (PCR) technique described by Olsson et al [24]. Amplification was performed for each subject with sense primers corresponding to normal and
GATA-1-mutated promoter sequence combined with antisense primers that discriminate the $F Y^{*} A$ and $F Y^{* \prime} B$ alleles in four different combinations of primer pairs. PCR mixtures included $100 \mathrm{ng}$ genomic DNA, $0.2 \mathrm{mM}$ of each primer, $100 \mathrm{mM}$ of each dNTP, $1.5 \mathrm{mM} \mathrm{MgCl} 2$, and $0.5 \mathrm{U}$ AmpliTaq Gold polymerase (Perkin Elmer, USA) in the AmpliTaq Gold buffer supplied by Perkin Elmer in a reaction volume of $25 \mu \mathrm{L}$. Mixtures were incubated for $8 \mathrm{~min}$ at $95^{\circ} \mathrm{C}$, followed by 10 cycles of $94^{\circ} \mathrm{C}$ for $1 \mathrm{~min}$ and $69^{\circ} \mathrm{C}$ for $1 \mathrm{~min}, 25$ cycles of $94^{\circ} \mathrm{C}$ for $1 \mathrm{~min}, 64^{\circ} \mathrm{C}$ for $1 \mathrm{~min}$ and $72^{\circ} \mathrm{C}$ for $1 \mathrm{~min}$, and a final incubation at $72^{\circ} \mathrm{C}$ for $10 \mathrm{~min}$. PCR products were separated electrophoretically using $1.5 \%$ agarose gel at 150 volts for $30 \mathrm{~min}$ and visualized with SYBR ${ }^{\circledR}$ Safe DNA gel stain under UV excitation.

\section{Statistical analysis}

Statistical analysis was undertaken using $x^{2}$ analysis to compare the proportions of Duffy genotypes alleles among in $P$. vivax-infected patients and sympatric malaria-exposed controls (P. falciparum-infected and non-infected individuals).

\section{Results}

Both Duffy genotyping and Plasmodium species diagnostic assays (qPCR-mtDNA method) were performed successfully for 678 individuals (330 urban, 166 of Vencedora and 182 of Luciana). Plasmodium spp. infection was detected in 137 samples (20.2\%), of which 57 (17.3\%) urban, 25 (15.1\%) of Vencedora and 55 (30.2\%) of Luciana. Overall prevalence of each Plasmodium species was 13.9\% (94/678) P. vivax, 5.8\% (39/678) P. falciparum, and 0.6\% $(4 / 678) P$. vivax + P. falciparum. In all of the study sites prevalence of $P$. vivax was the highest, ranging from $12.1 \%$ in urban patients to $17.6 \%$ in Villa Luciana. P. falciparum was found in only one patient of Vencedora (0.6\%), $16(4.8 \%)$ patients and in 22 urban (12.1\%) of Luciana. Overall, 4.3\% (29/678) were genotyped as Duffynegative (FY*BES/*BES) FY" $\mathrm{B}^{E S} / * \mathrm{~B}^{E S}$ and $95.7 \%(649 / 678)$ were Duffy positive. Among Duffy-negative individuals $6.9 \%(2 / 29)$ were $P$. vivax PCR positive based on the qPCR-mtDNA method, and among Duffy-positive 14.7\% (96/649) were P. vivax PCR positive. The two Duffynegative PCR positive for $P$. vivax were identified at Luciana (2/22 infected individuals). The risk of Duffynegatives to experience a $P$. vivax blood stage infection was lower but not significantly different to that of Duffy-positives (Odds ratio $=0.4460$; 95\% confidence interval 0.1044 - 1.9060; $\mathrm{P}=0.3983$ ).

Moreover, among $P$. vivax-infected patients (94 P. vivax mono-infections and four $P$. vivax/P. falciparum mixed infections), 2.0\% were Duffy-negative and the frequency of the allele $F Y^{* *} B^{E S}$ in this group was $18.6 \%$. Among P. falciparum-infected and non-infected individuals (sympatric malaria-exposed controls, $\mathrm{n}=584$ ) $4.6 \%$ were Duffy- 
negative $\left(F Y^{* \prime} B^{E S}\right.$ allele frequency of $\left.18.3 \%\right)$. In the total sample the frequency of allele $F Y^{\prime \prime} B^{E S}$ was $18.4 \%$. No significant differences were observed when comparing the genotypic and allelic frequencies of the Duffy blood group among Duffy-negative $P$. vivax-infected patients and controls both the total sample and in each of the three study sites, also suggesting no significant reduction of infection rates among the carriers of the $F Y^{* *} B^{E S}$ allele (Tables 1 and 2).

\section{Discussion}

The prevalence of P. vivax and P. falciparum and Duffyblood group genotype distribution was studied in the population of Anajás, State of Pará, an area of malaria transmission in the Brazilian Amazonian, in order to analyse the presence of $P$. vivax infection in Duffy-negative individuals.

Until recently, the Duffy-negative phenotype was seen as giving complete protection against infection by $P$. vivax, since this parasite requires the presence of Duffy antigen receptor for chemokines on the RBC surface to be able to invade cells and cause disease. However, the universality of this specificity has been questioned by recent reports that $P$. vivax infects and causes disease in Duffy-negative people in some parts of the world [16-21].

In this study, $6.9 \%(2 / 29)$ of the Duffy-negative subjects were diagnosed as $P$. vivax-infected, a finding that confirms previous reports in patients from Rondonia, western Brazilian Amazon [17,18], as well as in Kenya, East Africa [16], in Madagascar [19], Equatorial Guinea and Angola, African West Coast [20] and Mauritania, north-western Africa [21]. Moreover, the data obtained in the population of Anajás are in accordance with those found in children from Madagascar [19], where in individual study sites with sufficient numbers of PCR-positive P. vivax infections to enable comparisons, prevalence ratios were not significantly different between Duffy-positive and -negative children. That is, the risk of malaria infection due to $P$. vivax was not different between the Duffy-negative and Duffypositive groups.

It is of note that other genotypes besides Duffy-negative have been shown capable of influencing the susceptibility to $P$. vivax infection $[18,25]$, but this was not observed in Anajás, since the genotype frequencies did not differ

Table 1 Duffy genotyping and Plasmodium species diagnosis in the population of Anajás, State of Pará, Brazil

\begin{tabular}{|c|c|c|c|c|}
\hline Place & Duffy genotypes & Controls* & $P$. vivax-infecteds & p-value \\
\hline \multirow[t]{6}{*}{ City of Anajás } & $F Y^{*} A{ }^{*} A$ & $83(28.6 \%)$ & $12(30.0 \%)$ & 0.9955 \\
\hline & $F Y^{*} A /^{*} B$ & 97 (33.4\%) & $10(25.0 \%)$ & 0.3735 \\
\hline & $F Y^{*} A{ }^{*} B E S$ & $40(13.8 \%)$ & $7(17.5 \%)$ & 0.6983 \\
\hline & $F Y^{*} B /^{*} B$ & $36(12.4 \%)$ & $7(17.5 \%)$ & 0.5188 \\
\hline & $F Y^{*} B /{ }^{*} B E S$ & $24(8.3 \%)$ & $4(10.0 \%)$ & 0.9488 \\
\hline & $F Y^{*} B E S /{ }^{*} B E S$ & $10(3.4 \%)$ & $0(0.0 \%)$ & 0.4835 \\
\hline \multirow[t]{6}{*}{ Vencedora } & $F Y^{*} A{ }^{*} A$ & $29(20.1 \%)$ & $5(22.7 \%)$ & 0.9973 \\
\hline & $F Y^{*} A /^{*} B$ & $44(30.6 \%)$ & $4(18.2 \%)$ & 0.3473 \\
\hline & $F Y^{*} A /^{*} B^{E S}$ & $21(14.6 \%)$ & $3(13.6 \%)$ & 0.8354 \\
\hline & $F Y^{*} B /{ }^{*} B$ & 19 (13.2\%) & $4(18.2 \%)$ & 0.7647 \\
\hline & $F Y^{*} B /{ }^{*} B^{E S}$ & $26(18.1 \%)$ & $4(18.2 \%)$ & 0.7771 \\
\hline & $F Y^{*} B^{E S} / * B^{E S}$ & $5(3.5 \%)$ & $2(9.1 \%)$ & 0.5145 \\
\hline \multirow[t]{6}{*}{ Luciana } & $F Y^{*} A /^{*} A$ & $36(24.0 \%)$ & $8(25.0 \%)$ & 0.9144 \\
\hline & $F Y^{*} A{ }^{*} B$ & $29(19.3 \%)$ & 7 (21.9\%) & 0.9336 \\
\hline & $F Y^{*} A /^{*} B^{E S}$ & 29 (19.3\%) & $5(15.6 \%)$ & 0.8112 \\
\hline & $F Y^{*} B /{ }^{*} B$ & $24(16.0 \%)$ & $4(12.5 \%)$ & 0.8194 \\
\hline & $F Y^{*} B{ }^{*} B^{E S}$ & $20(13.3 \%)$ & $8(25.0 \%)$ & 0.1643 \\
\hline & $F Y^{*} B^{E S} /{ }^{*} B^{E S}$ & $12(8.0 \%)$ & $0(0.0 \%)$ & 0.2065 \\
\hline \multirow[t]{6}{*}{ Total population } & $F Y^{*} A{ }^{*} A$ & 147 (25.3\%) & $26(26.5 \%)$ & 0.2106 \\
\hline & $F Y^{*} A{ }^{*} B$ & 169 (29.1\%) & $22(22.4 \%)$ & 0.8606 \\
\hline & $F Y^{*} A /^{*} B E S$ & $90(15.5 \%)$ & $15(15.3 \%)$ & 0.6765 \\
\hline & $F Y^{*} B /{ }^{*} B$ & $78(13.4 \%)$ & $16(16.3 \%)$ & 0.9430 \\
\hline & $F Y^{*} B{ }^{*} B^{E S}$ & $69(11.9 \%)$ & $17(17.3 \%)$ & 0.0662 \\
\hline & $F Y^{*} B^{E S} /{ }^{*} B^{E S}$ & 27 (4.7\%) & $2(2.0 \%)$ & 0.2634 \\
\hline
\end{tabular}




\begin{tabular}{|c|c|c|c|c|}
\hline Place & Alelles & Controls ${ }^{*}$ & P. vivax-infecteds & $p$-value \\
\hline \multirow[t]{3}{*}{ City of Anajás } & $F Y^{*} A$ & $303(52.2 \%)$ & $41(51.3 \%)$ & 0.9625 \\
\hline & $F Y^{*} B$ & 193 (33.3\%) & $28(35.0 \%)$ & 0.8572 \\
\hline & $F Y^{*} B^{E S}$ & $84(14.5 \%)$ & $11(13.8 \%)$ & 0.9959 \\
\hline \multirow[t]{3}{*}{ Vencedora } & $F Y^{*} A$ & $123(42.7 \%)$ & 17 (38.6\%) & 0.7297 \\
\hline & $F Y^{*} B$ & $108(37.5 \%)$ & $16(36.4 \%)$ & 0.9823 \\
\hline & $F Y^{*} B^{E S}$ & $57(19.8 \%)$ & $11(25.0 \%)$ & 0.5507 \\
\hline \multirow[t]{3}{*}{ Luciana } & $F Y^{*} A$ & 130 (43.3\%) & $28(43.8 \%)$ & 0.9380 \\
\hline & $F Y^{*} B$ & 97 (32.3\%) & $23(35.9 \%)$ & 0.6815 \\
\hline & $F Y^{*} B^{E S}$ & $73(24.3 \%)$ & $13(20.3 \%)$ & 0.5993 \\
\hline \multirow[t]{3}{*}{ Total population } & $F Y^{*} A$ & $553(47.7)$ & $89(45.4)$ & 0.5378 \\
\hline & $F Y^{*} B$ & $394(34.0)$ & $71(36.2)$ & 0.5571 \\
\hline & $F Y^{*} B^{E S}$ & $213(18.4)$ & $36(18.4)$ & 0.9986 \\
\hline
\end{tabular}

*patients infected with $P$. falciparum and non-infected individuals.

significantly between controls and $P$. vivax-infected patients both in the whole sample and in each site investigated. One possible explanation for the results obtained in Anajás would be that the intensity of transmission of $P$. vivax in this region is such that it provides a constant source of parasites that infect Duffy-positives, providing ample opportunities for infection of hepatocytes Duffynegative and selecting strains of $P$. vivax with a new capacity to invade erythrocytes, possibly through a Duffy-independent mechanism. In this scenario, less prominent protective effects against infection by $P$. vivax conferred by other genotypes seem to have been abolished or are less evident.

This study was unable to assess possible effects of Duffy genotypes on the risk of developing clinical malaria, since the patients were not followed after medical attention. Anyway, it is important to note that only one of the two Duffy-negative patients diagnosed as $P$. vivaxinfected through mtDNA-qPCR method was confirmed by microscopic examination of blood smear, and had parasitemia classified as low (12 parasites per field under oil immersion microscope). The other patient was only detected by $\mathrm{qPCR}$, but also presented a profile consistent with low parasitemia. In addition, with respect to clinical manifestations, both were asymptomatic at the time of medical consultation.

The observed frequencies of Duffy-negative genotype in P. vivax patients and controls in Anajás population (2.1\% and $4.6 \%$, respectively), which are not significantly different, are smaller than those found in Afro-Brazilian communities in eastern Amazonia (Pará and Amapá) [26], in which the genotype frequencies ranged from 0.323 to 0.588 , but are quite similar to those found in most Amazonian populations already studied (frequencies ranging from 0 to $12 \%$ )
$[17,18,27,28]$. Moreover, the frequencies of Duffy genotypes found in Anajás are the expected for a population with a genetic background resulting from the admixture between Europeans, mainly Portuguese, Africans and Amerindians in very close proportions [29]. Thus, the observed distribution of Duffy genotypes in the population of Anajás with a high frequency of Duffy-positive associated with a high prevalence of malaria, predominantly $P$. vivax, appears to fulfil the conditions considered by Ménard et al [19] as necessary to clear the barrier of Duffy negativity, providing conditions for the parasites have sufficient exposure to Duffy-negative red cells, allowing more opportunities for de novo selection or optimization of an otherwise cryptic invasion pathway that nevertheless seems less efficient than the Duffy-dependent pathway.

\section{Conclusions}

The data obtained in the population of Anajás showed no differential resistance to $P$. vivax infection among Duffy-negative and Duffy-positive, a result that needs to be corroborated by further evaluation in a larger sample of patients with $P$. vivax malaria, and by molecular characterization of the parasite in order to evaluate the diversity of strains of $P$. vivax circulating in this area, coupled with the ability to invade erythrocytes using other receptors than Duffy. However, this result could mean that new capacity of the parasite may be relatively common in the population of Anajás through adaptive mechanisms and evolutionary processes that deserve to be investigated, and that this genetic profile of the parasite, resulting in the loss of an important protective mechanism against vivax malaria, may be contributing significantly to increase the susceptibility to infection by $P$. vivax and, consequently, to the high incidence of malaria in the municipality of Anajás.

\section{Competing interests}

The authors declare that they have no competing interests.

\section{Authors' contributions}

JFG, TAAC conceived and designed the experiments; TAAC, MGQ, GLC, IGD performed the experiments; JFG analysed the data wrote the paper; JFG, TAAC, MGQ, AYNP carried out the biological material and data collection in the field. All authors read and approved the final manuscript.

\section{Acknowledgements}

We thank all people who accepted to participate in this study. We thank technicians from the Municipal Health Department of Anajás.

This study was supported by Conselho Nacional de Desenvolvimento Científico e Tecnológico (CNPq), Brasil, Edital MCT/CNPq/CT-Saúde/MS/SCTIE/ DECIT No 034/2008 Doenças Negligenciadas, Processo 576296/2008-2, and by Universidade Federal do Pará (UFPA).

\section{Author details}

'Laboratório de Genética Humana e Médica, Instituto de Ciências Biológicas, Universidade Federal do Pará, Cidade Universitária Prof. José da Silva Neto, Rua Augusto Corrêa, No 1, Guamá, CEP 66075-110, Belém, PABrasil. ${ }^{2}$ Instituto Evandro Chagas, Programa de Malária, Belém, Pará, Brasil. 
Received: 31 October 2012 Accepted: 16 December 2012

Published: 22 December 2012

\section{References}

1. Oliveira-Ferreira J, Lacerda MVG, Brasil P, Ladislau JLB, Tauil PL, Daniel-Ribeiro CT: Malaria in Brazil: an overview. Malar J 2010, 115:115-128.

2. Ministério da Saúde: Sistema de Informação e Vigilância Epidemiológica da Malária. SIVEP/Malária. http://portalweb04.saude.gov.br/sivep_malaria/ default.asp.

3. Mercereau-Puijalon O, Ménard D: Plasmodium vivax and the Duffy antigen: A paradigm revisited. Transfus Clin Biol 2010, 17:176-183.

4. Carter R: Speculations on the origins of Plasmodium vivax malaria. Trends Parasitol 2003, 19:214-219.

5. Rosenberg R: Plasmodium vivax in Africa: hidden in plain sight? Trends Parasitol 2007, 23:193-196.

6. Howes RE, Patil AP, Piel FB, Nyangiri OA, Kabaria CW, Gething PW, Zimmerman PA, Barnadas C, Beall CM, Gebremedhin A, Ménard D, Williams TN, Weatherall DJ, Hay SI: The global distribution of the Duffy blood group. Nat Commun 2011, 2:266.

7. Donahue RP, Bias WB, Renwick JH, McKusick VA: Probable assignment of the Duffy blood group locus to chromosome 1 in man. Proc Natl Acad SCl USA 1968, 61:949-955.

8. Chaudhuri A, Polyakova J, Zbrzezna V, Pogo AO: The coding sequence of Duffy blood group gene in humans and simians: restriction fragment length polymorphism, antibody and malarial parasite specificities, and expression in nonerythroid tissues in Duffy-negative individuals. Blood 1995, 85:615-621.

9. Iwamoto S, Omi T, Kajii E, Ikemoto S: Genomic organization of the glycoprotein D gene: Duffy blood group Fya/Fyb alloantigen system is associated with a polymorphism at the 44 -amino acid residue. Blood 1995, 85:622-626

10. Mallinson G, Soo KS, Schall TJ, Pisacka M, Anstee DJ: Mutation in the erythrocyte chemokine receptor (Duffy) gene: the molecular basis of the Fya/Fyb antigens and identification of a deletion in the Duffy gene of an apparently healthy individual with the Fy(a-b-) phenotype. Brit J Hematol 1995, 90:823-829.

11. Tournamille C, Le Van Kim C, Gane P, Cartron JP, Colin Y: Molecular basis and PCR-DNA typing of the Fya/fyb blood group polymorphism. Hum Genet 1995, 95:407-410.

12. Pogo $A O$, Chaudhuri $A$ : The Duffy protein: a malarial and chemokine receptor. Semin Hematol 2000, 37:122-129.

13. Tournamille C, Colin Y, Cartron JP, Kim CLV: Disruption of a GATA motif in the Duffy gene promoter abolishes erythroid gene expression in Duffy-negative individual. Nat Genet 1995, 10:224-228.

14. Zimmerman PA, Woolley I, Masinde GL, Miller SM, McNamara DT, Hazlett F, Mgone CS, Alpers MP, Genton B, Kazura JW: Emergence of FY*A (null) in a Plasmodium vivax-endemic region of Papua New Guinea. Proc Natl Acad Sci USA 1999, 96:13973-13977.

15. Kasehagen LJ, Mueller I, Kiniboro B, Bockarie MJ, Reeder JC, Kazura JW, Kastens W, McNamara DT, King CH, Whalen CC, Zimmerman PA: Reduced Plasmodium vivax erythrocyte infection in PNG Duffy-negative heterozygotes. PLoS One 2007, 2:336.

16. Ryan JR, Stoute JA, Amon J, Dunton RF, Mtalib R, Koros J, Owour B, Luckhart S, Wirtz RA, Barnwell JW, Rosenberg R: Evidence for transmission of Plasmodium vivax among a Duffy antigen negative population in Western Kenya. Am J Trop Med Hyg 2006, 75:575-581.

17. Cavasini CE, Mattos LC, Couto AA, Bonini-Domingos CR, Valencia SH, Neiras WC, Alves RT, Rossit AR, Castilho L, Machado RL: Plasmodium vivax infection among Duffy antigen negative individuals from the Brazilian Amazon region: an exception? Trans R Soc Trop Med Hyg 2007, 101:1042-1044.

18. Cavasini CE, Mattos LC, Couto AA, Bonini-Domingos CR, Valencia SH, Neiras WC, Alves RT, Rossit AR, Castilho L, Machado RL: Duffy blood group gene polymorphisms among malaria vivax patients in four areas of the Brazilian Amazon region. Malar J 2007, 6:167.

19. Ménard D, Barnadas C, Bouchier C, Henry-Halldin C, Gray R, Ratsimbasoa A, Thoniera V, Carodf JF, Domarlea O, Coling Y, Bertrandg O, Picotg J, King CL, Grimbergc BT, Mercereau-Puijalonb O, Zimmerman PA: Plasmodium vivax clinical malaria is commonly observed in Duffy-negative Malagasy people. Proc Natl Acad Sci USA 2010, 107:5967-5971.
20. Mendes C, Dias F, Figueiredo J, Mora VG, Cano J, Sousa B, Rosário VE, Benito A, Berzosa P, Arez AP: Duffy negative antigen is no longer a barrier to Plasmodium vivax - molecular evidences from the African West Coast (Angola and Equatorial Guinea). PLoS Negl Trop Dis 2011, 5:e1192.

21. Wurtz N, Lekweiry KM, Bogreau H, Pradines B, Rogier C, Boukhary AOMS, Hafid JE, Salem MSOA, Trape JF, Basco LK, Briolant S: Vivax malaria in Mauritania includes infection of a Duffy-negative individual. Malar J 2011, 10:336.

22. Doenças de A a Z; 2010. http://portal.saude.gov.br/portal/saude/profissional/ areacfm?id_area $=1526$

23. Manual de diagnóstico laboratorial da malária; 2005. http://portal.saude.gov. $\mathrm{br} /$ portal/arquivos/pdf/manual_diagnostico_malaria.pdf.

24. Olsson ML, Hansson C, Avent ND, Akesson IE, Green CA, Daniels GL: A clinically applicable method for determining the three major alleles at the Duffy (FY) blood group locus using polymerase chain reaction with allele-specific primers. Transfusion 1998, 38:168-173.

25. King $\mathrm{CL}$, Adams JH, Xianli J, Grimberg BT, McHenry AM, Greenberg LJ, Siddiqui A, Howes RE, da Silva-Nunes M, Ferreira MU, Zimmerman PA: Fy(a)/ $\mathrm{Fy}(\mathrm{b})$ antigen polymorphism in human erythrocyte Duffy antigen affects susceptibility to Plasmodium vivax malaria. Proc Natl Acad Sci USA 2011, 108:20113-20118.

26. Perna SJQ, Cardoso GL, Guerreiro JF: Duffy blood group genotypes among African Brazilian communities of the Amazon region. Genet Mol Res 2007, 6:166-172.

27. Cavasini CE, Pereira FJT, Ribeiro WL, Wunderlich G, Ferreira MU: Duffy blood group genotypes among malaria patients in Rondônia, Western Brazilian Amazon. Rev Soc Bra Med Trop 2001, 34:591-595.

28. Albuquerque SRL, Cavalcante FO, Sanguino EC, Tezza L, Castilho FCL, Santos MC: FY polymorphisms and vivax malaria in inhabitants of Amazonas State, Brazil. Parasitol Res 2010, 106:1049-1053.

29. Santos SEB, Santos AKCR, Santos EJM, Guerreiro JF: The Amazon microcosm. Ciência e Cultura 1999, 51:181-190.

doi:10.1186/1475-2875-11-430

Cite this article as: Carvalho et al:: Plasmodium vivax infection in Anajás, State of Pará: no differential resistance profile among Duffy-negative and Duffy-positive individuals. Malaria Journal 2012 11:430.

\section{Submit your next manuscript to BioMed Central and take full advantage of:}

- Convenient online submission

- Thorough peer review

- No space constraints or color figure charges

- Immediate publication on acceptance

- Inclusion in PubMed, CAS, Scopus and Google Scholar

- Research which is freely available for redistribution 